\title{
Identification of individual coconut crabs, Birgus latro, on the basis of the pattern of grooves on the carapace
}

Shin-ichiro Oka, Shohei Matsuzaki, and Minoru Toda

\begin{abstract}
We identified individual coconut crabs, Birgus latro, on the basis of photographic matching of the grooving patterns on the carapace. The photographic matching was performed using 336 front cephalothorax photographs obtained during night searching (capture and release) from 2006 to 2012 in Ocean Expo Park, southern Japan. Grooving patterns were visually matched on the basis of the distribution, form, and number of grooves. We determined that 99 individuals were captured and photographed twice. The period between release and recapture ranged from 2 to 2224 days. The grooving pattern on the carapace was unchanged, even when there were more than 1500 days between release and capture. In addition, captive crab maintained the same grooving pattern through four molts. Therefore, photographic matching of carapace grooving patterns is a useful technique for long-term individual identification. Crabs identified using this method are safer to consume than those tagged using invasive tagging methods, including passive integrated transponder tags. Photographic matching is also a useful way to identify individuals in the harvested population.
\end{abstract}

\section{Introduction}

The coconut crab, Birgus latro, is widely distributed in the tropical islands of the Indian and Pacific Oceans. This species is in decline in many of the remaining island populations, most likely because of harvesting for human consumption and as a consequence of habitat loss (Drew et al., 2010). Because several countries are aware of the need for resource management strategies, ecological information has been accumulated by many researchers (Drew et al., 2010).

Identification of individuals in the field could allow researchers to gather ecological information that is useful for resource management (e.g., growth, migration, and population size). Fletcher et al. (1989) reported that marking with heat branding has been useful for identifying coconut crabs. Passive integrated transponder (PIT) tags have also been applied to the coconut crab (Drew et al., 2012; Sato et al., 2013). In addition, Krieger et al., (2012) used GPSbased telemetric studies to examine their migration behavior. However, natural features or markings have been used to identify individuals of some crustacean species (MacDiarmid et al., 2005; Gallardo-Escarate et al., 2007; Gosselin et al., 2007). There are many grooved and ridged patterns on the carapace of the coconut crab. In this paper, we introduce a new method for identifying coconut crabs on the basis of natural marks on the carapace.

Materials and Methods

Collection of crabs and field investigations

A total of 202 night searches were performed from June 2006 to October 2012 in the Ocean Expo Park $\left(26^{\circ} 41^{\prime} \mathrm{N}, 127^{\circ} 52^{\prime} \mathrm{E}\right.$; ca. 77 ha), Okinawa, southern Japan. When crabs were found, thoracic length (TL; see Fletcher et al., 1990) was measured to the nearest $0.1 \mathrm{~mm}$ by using a vernier caliper, and sex was recorded. A dorsal view of each carapace was photographed using a digital camera. All crabs captured between 2006 and $2010(\mathrm{n}=162)$ were marked with an individual code on the thoracic area by using white oil-based paint to determine how long the paint codes remained on the crab. The recorded individuals were then released 


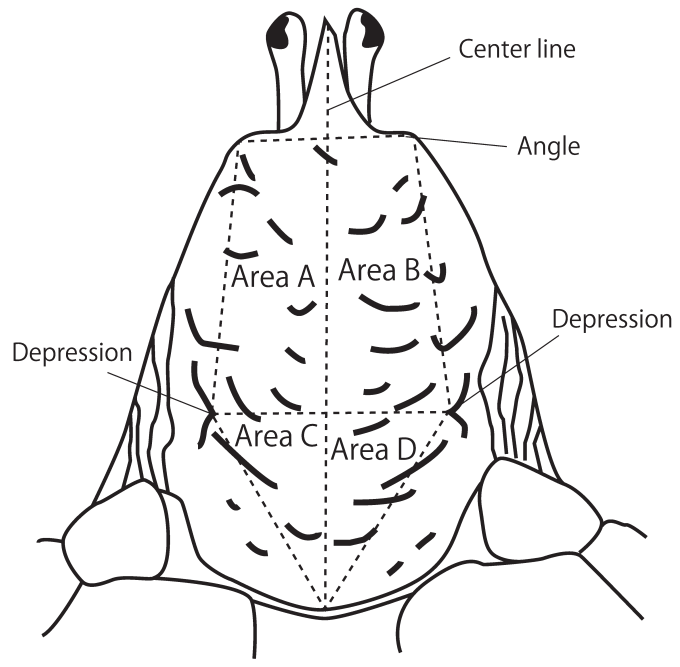

Fig. 1. Schematic diagram of four carapace areas (AD) on the front cephalothorax in which grooves were counted. The grooves that crossed borders between areas were counted in each area where they were found.

where they were found.

\section{Carapace pattern matching}

There are many grooved and ridged patterns on the carapaces of coconut crabs. The patterns on the legs are hidden during handling, and those on thoracic area are not clear enough for paint marking. Therefore, patterns on the front cephalothorax area were used for pattern matching in this study. The digital images of the dorsal view of each crab were cropped so that only the front cephalothorax area remained. These photographs were arranged in pairs on a computer monitor using Windows Media Player (Microsoft) and were visually matched on the basis of the distribution, form, and number of the grooves on the front cephalothorax one pair at a time. For recaptured crabs with more than 1500 days between captures (20 cases), the number of grooves in four areas (A-D, see Fig. 1) were counted in order to examine any longterm changes in the grooving pattern. The examined areas were contained within the front angle of the cephalothorax, the paired depression on the lateral carapace, and the end of the center line. The examined areas were divided by the center line of the cephalothorax and a reference line between the paired depressions (Fig. 1). Grooves that crossed borders between areas were counted in each area in which they were found.

Rearing experiment

A single small crab (7.2 $\mathrm{mm}$ TL) was collected from Miyako Island, Okinawa Prefecture, Japan, and kept from July 2010 to February 2013. The crab was housed in cage that was made from clear acrylic fiber $(18 \times$ $18 \times 18 \mathrm{~cm})$. Ceramic soil covered half of the depth of the cage. Food (e.g., dried shrimp, fruits, vegetables) was replaced every day. After the $2^{\text {nd }}$ molt, when the crab shed its shell, after the $4^{\text {th }}$ molt, and after the $6^{\text {th }}$ molt, photographs of the dorsal view of the carapace were taken using a digital camera. The grooving pattern in each photograph was visually compared as described above. Photographs of carapace grooving patterns could not be taken prior to the $2^{\text {nd }}$ molt, as doing so would require forcible extraction of the crab from its shell.

\section{Results}

\section{Carapace pattern matching of wild crabs}

Of the carapace photographs of 336 crabs (females: $\mathrm{n}=140,14.3-47.5 \mathrm{~mm} \mathrm{TL}$; males: $\mathrm{n}=196,17.8-68.6 \mathrm{~mm}$ TL) examined, 99 pairs were judged to be recaptured individuals, based on the distribution and form of the carapace grooves. These 99 matches were possible even though the photographic angle differed in some cases (see Fig. 2-E). There were no questionable cases. Even when two crabs had a similar pattern in one part of the carapace, the pattern was clearly different in the other parts. The

Fig. 2. Groove patterns of the front cephalothorax of wild coconut crabs collected from Ocean Expo Park, southern Japan. Left: photographs taken at release. Right: pattern-matched crabs (that were recaptured) after more than 1500 days. The groove pattern is emphasized as solid lines. Dashed lines indicate the borders of each carapace area in Figure 1. A-G correspond to the individual numbers in Table 1 as follows: A, No. 1; B, No. 3; C, No. 4; D, No. 5; E, No. 8; F, No. 12 ; G, No. 13 ; H, No. 15 . 

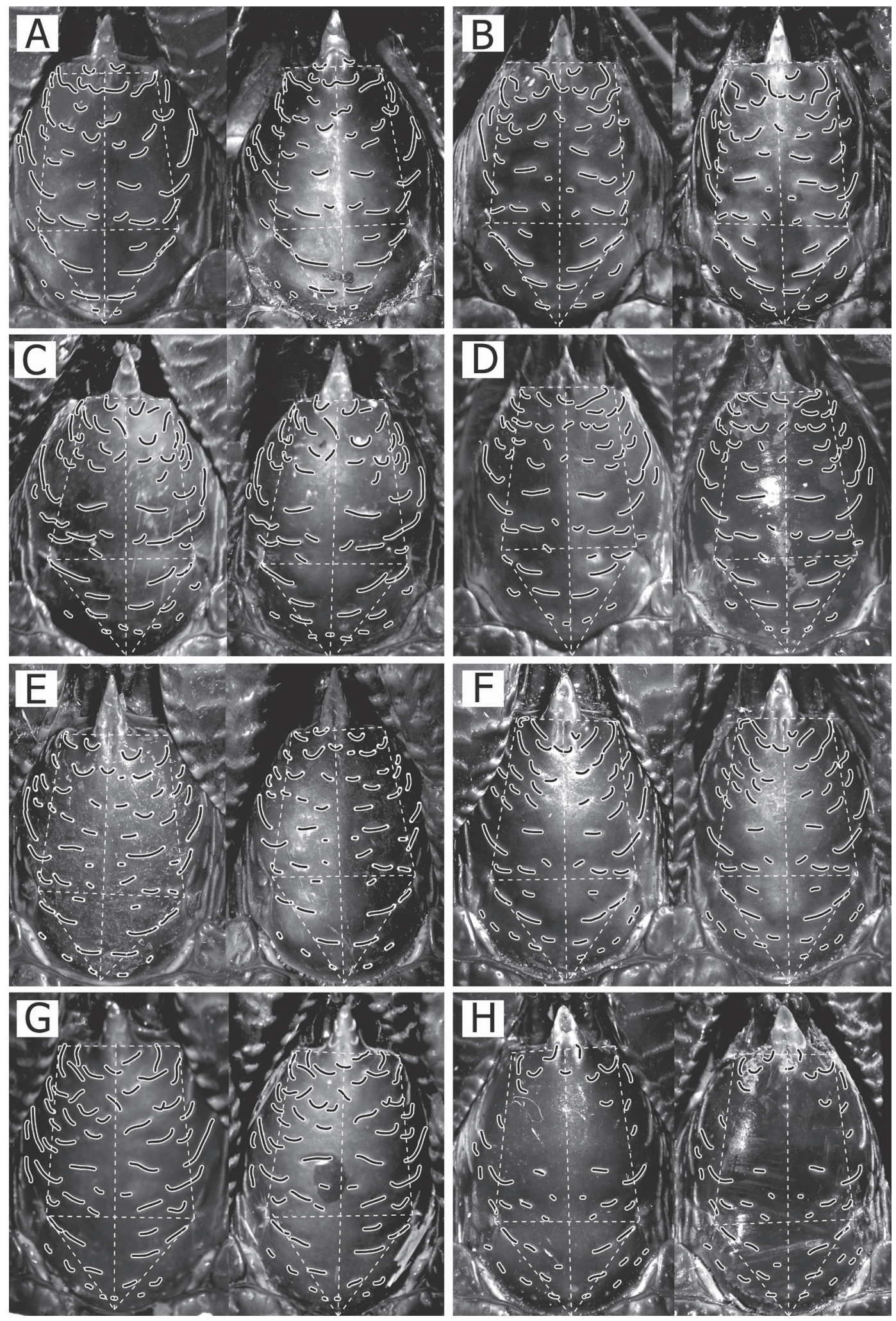


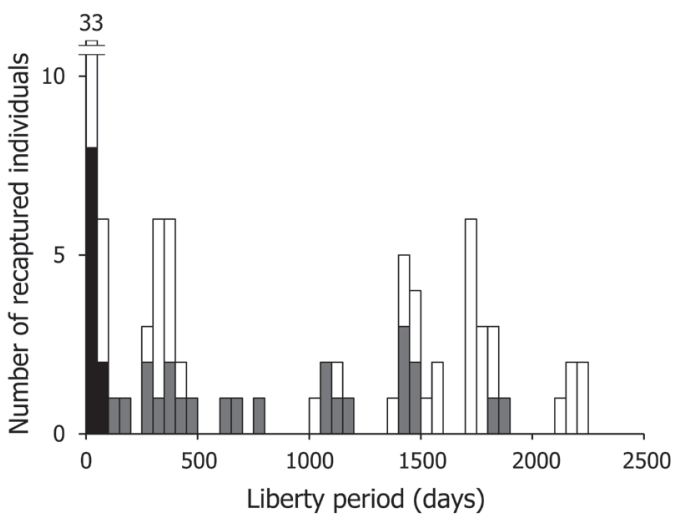

Fig. 3. Frequency of recapture of wild coconut crabs $(n=99)$ in Ocean Expo Park, southern Japan. Liberty period is the period between day of release day and day on which a crab with the same carapace markings was recaptured. Solid and gray areas indicate crabs with paint marks on the thoracic carapace and those which have lost their paint marks but can still be recognized using natural marking. Open areas indicate unpainted crabs. period between release and recapture ranged from 2 to 2224 days (Fig. 3). The TL of 48 recaptured crabs increased between captures, which indicates that these crabs molted at least once between recaptures. The grooving pattern on the carapace was unchanged, even for those crabs with liberty periods that were longer than 1500 days (Fig. 2). The number of grooves in each carapace area (see Fig. 1) was also unchanged between initial capture and recapture (Table 1). Thirty-three painted crabs were later recaptured. The paint marks were present on all crabs recaptured within 66 days of release (10 cases), but had disappeared on those crabs recaptured more than 71 days after release (Fig. 3).

\section{Carapace pattern of captive crabs}

The dates of each molt and the TLs after molting for the captive crab were as follows: $1^{\text {st }}$ molt, 16 December $2010,8.5 \mathrm{~mm} ; 2^{\text {nd }}$,

Table 1. Number of groove marks in each area on the front cephalothorax (A-D, see figure 1) of wild coconut crabs recaptured more than 1500 days after release. $\mathrm{TL}_{1}$ : the thoracic length at release; $\mathrm{TL}_{2}$ : the thoracic length at recapture. Numbers in parentheses indicate the number of grooves at recapture.

\begin{tabular}{|c|c|c|c|c|c|c|c|c|c|}
\hline \multirow[t]{2}{*}{ No. } & \multirow[t]{2}{*}{$\begin{array}{l}\text { Liberty period } \\
\text { (days) }\end{array}$} & \multirow[t]{2}{*}{ Sex } & \multirow[t]{2}{*}{$\mathrm{TL}_{1}$} & \multirow[t]{2}{*}{$\mathrm{TL}_{2}$} & \multirow[t]{2}{*}{$\begin{array}{l}\text { increments } \\
(\mathrm{mm})\end{array}$} & \multicolumn{4}{|c|}{$\begin{array}{l}\text { Number of grooving marks } \\
\text { at release (at recapture) }\end{array}$} \\
\hline & & & & & & A & $\mathrm{B}$ & $\mathrm{C}$ & $\mathrm{D}$ \\
\hline 1 & 2224 & Male & 44.3 & 60.3 & 16.0 & 18 (18) & $12(12)$ & $4(4)$ & $5(5)$ \\
\hline 2 & 2203 & Male & 56.1 & 61.4 & 5.3 & $14(14)$ & 14 (14) & $4(4)$ & $4(4)$ \\
\hline 3 & 2175 & Female & 39.6 & 42.2 & 2.6 & 19 (19) & $18(18)$ & $6(6)$ & $4(4)$ \\
\hline 4 & 2159 & Female & 25.3 & 40.1 & 14.8 & $16(16)$ & $14(14)$ & $5(5)$ & $5(5)$ \\
\hline 5 & 2141 & Female & 21.0 & 31.0 & 10.0 & 17 (17) & $16(16)$ & $6(6)$ & $6(6)$ \\
\hline 6 & 1854 & Female & 28.9 & 34.4 & 5.5 & 13 (13) & $14(14)$ & $2(2)$ & $4(4)$ \\
\hline 7 & 1848 & Male & 38.6 & 57.2 & 8.6 & 17 (17) & 17 (17) & $6(6)$ & $6(6)$ \\
\hline 8 & 1810 & Male & 32.3 & 39.5 & 7.2 & $16(16)$ & 18 (18) & $5(5)$ & $3(3)$ \\
\hline 9 & 1801 & Female & 38.3 & 40.1 & 1.8 & $22(22)$ & 17 (17) & $8(8)$ & $7(7)$ \\
\hline 10 & 1798 & Female & 41.0 & 43.5 & 2.5 & $15(15)$ & $16(16)$ & $4(4)$ & $2(2)$ \\
\hline 11 & 1771 & Female & 38.4 & 39.5 & 1.1 & $20(20)$ & $16(16)$ & $4(4)$ & $4(4)$ \\
\hline 12 & 1751 & Male & 30.6 & 39.2 & 8.6 & 17 (17) & $15(15)$ & $5(5)$ & $5(5)$ \\
\hline 13 & 1750 & Female & 35.4 & 38.9 & 3.5 & $22(22)$ & 19 (19) & $5(5)$ & $5(5)$ \\
\hline 14 & 1745 & Male & 38.5 & 40.7 & 2.2 & $11(11)$ & $11(11)$ & $4(4)$ & $3(3)$ \\
\hline 15 & 1728 & Female & 39.4 & 42.0 & 2.6 & $12(12)$ & $11(11)$ & $5(5)$ & $4(4)$ \\
\hline 16 & 1724 & Male & 31.9 & 38.2 & 6.3 & 18 (18) & $16(16)$ & $4(4)$ & $3(3)$ \\
\hline 17 & 1717 & Female & 28.1 & 32.1 & 4.0 & 18 (18) & $15(15)$ & $4(4)$ & $4(4)$ \\
\hline 18 & 1598 & Female & 38.3 & 39.8 & 1.5 & $16(16)$ & 14 (14) & $5(5)$ & $4(4)$ \\
\hline 19 & 1571 & Female & 32.9 & 34.0 & 1.1 & 19 (19) & $22(22)$ & $5(5)$ & $5(5)$ \\
\hline 20 & 1530 & Female & 32.3 & 33.8 & 1.5 & 14 (14) & 14 (14) & $4(4)$ & $3(3)$ \\
\hline
\end{tabular}




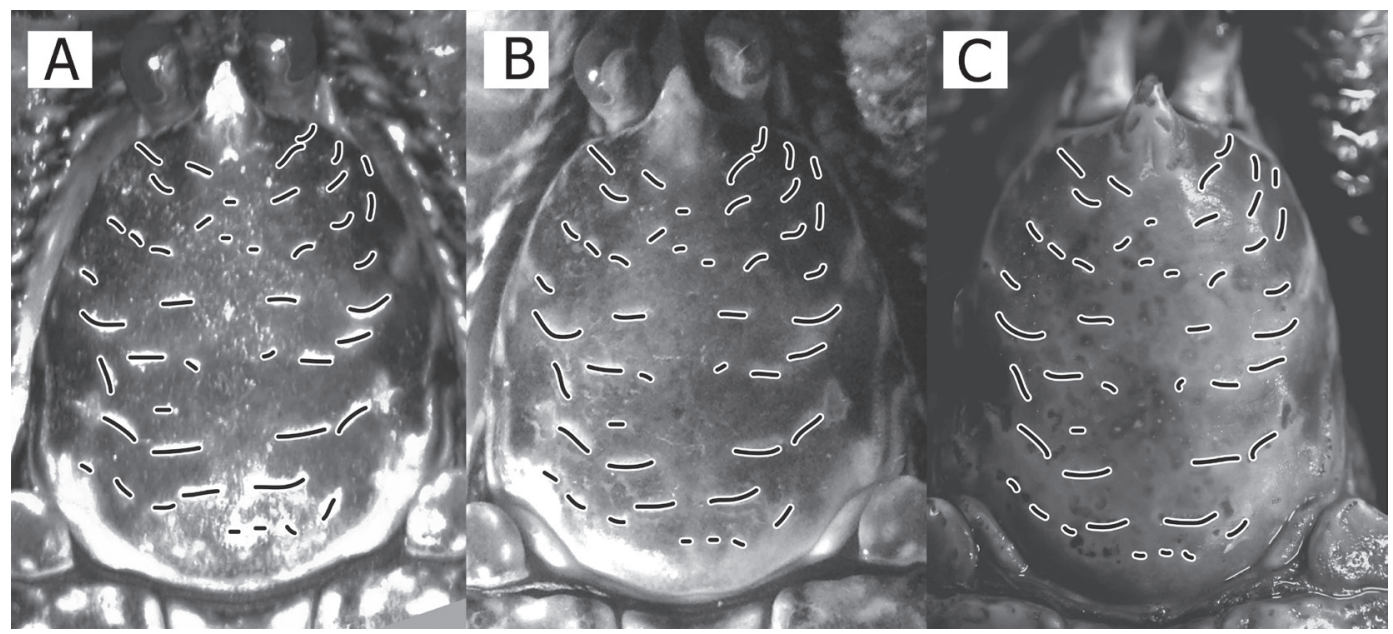

Fig. 4. Dorsal view of the front cephalothorax of a captive coconut crab. The groove pattern is emphasized as solid lines. A: after the $2^{\text {nd }}$ molt $(9.1 \mathrm{~mm} \mathrm{TL})$; B: after the $4^{\text {th }}$ molt $(12.0 \mathrm{~mm} \mathrm{TL})$; C: after the $6^{\text {th }}$ molt $(12.9 \mathrm{~mm} \mathrm{TL})$.

25 April 2011, $9.1 \mathrm{~mm} ; 3^{\text {rd }}, 25$ August $2011,10.7 \mathrm{~mm} ; 4^{\text {th }}, 3$ November $2011,12.0$ $\mathrm{mm} ; 5^{\text {th }}, 7$ June $2012,12.3 \mathrm{~mm}$; and $6^{\text {th }}, 6$ November 2012, $12.9 \mathrm{~mm}$. The crab died on 4 February 2013 from an unknown cause. The molting interval ranged from 70 to 217 days. The average ( \pm standard deviation) increment (pre-molting TL / post-molting TL) was $1.10 \pm 0.07$. The grooving patterns on the front cephalothorax of the captive crab were unchanged between the $2^{\text {nd }}$ and the $6^{\text {th }}$ molt (Fig. 4).

\section{Discussion}

The grooving pattern on the front cephalothorax of the captive crab was persistent through at least four molts (Fig. 4). Similarly, grooving patterns were unchanged in wild crabs, even when there were more than 1500 days between capture and recapture, including crabs with more than 6 years between capture and recapture (Fig. 2, Table 1). The increases in TL during long liberty periods (1530-2224 days) were 1.1-18.6 mm (Table 1). Crabs larger than 30 $\mathrm{mm}$ TL molt annually and have progressively smaller growth increments at each moult as they became larger (Fletcher et al. 1990). The annual growth increments of crabs larger than $30 \mathrm{~mm}$ TL in a southern Japanese population were estimated to be less than ca. $1 \mathrm{~mm}$ for females and $2.5 \mathrm{~mm}$ for males (Sato et al., 2013). Thus, the wild crabs in the present study with a long capture-recapture interval certainly molted one or more times between photographs (Table 1). The unique grooving patterns on the front cephalothorax are conserved for a long period, not only in captive crabs, but also in wild crabs. This result indicates that matching of the grooving pattern on the carapace is a useful technique for long-term individual identification of coconut crabs.

The use of natural features or markings to identify individuals, although common in studies of mammal behavior and ecology (e.g., Friday et al., 2000; Gope et al., 2005.), has been much less used in crustacean studies. MacDiarmid et al. (2005) used distinctive markings on the pedate processes around the rostrum, the epistome, and the antennular plate of the lobster, Jasus edwardsii. GallardoEscarate et al. (2007) reported distinctive color patterns on the cephalothorax of rock shrimp, Rhynchocinetes typus. Gosselin et al. (2007) found that the branchial ridges and pterygostomial spines of the cephalothorax of snow crab, Chionoecetes opilio, presented distinctive features for individual 
identification. These natural marks persisted after one or two molts. Our result confirmed that grooving patterns on the carapace of coconut crabs can be used to identify individuals over a long period. Although the identification characters for crustaceans vary by species, biologists should be able to find appropriate natural marks for other species in future studies.

Paint markings on the carapace of wild coconut crabs became unclear after 71 days. Moreover, these markings would be removed by molting, and are unsuitable for long-term monitoring. Fletcher et al. (1989) used heat branding to mark the carapaces of crabs. However, this method is limited to a single intermolt period because the markings become unclear after molting. Kringer et al. (2012) used GPS-based telemetric studies to estimate the migration behavior of crabs. This method is suitable for detailed documentation of the movements of crabs in remote situations, but the equipment is costly and tracking time is limited by battery life. Recently, passive integrated transponder (PIT) tags have been applied to coconut crabs (Drew et al., 2012; Sato et al., 2013). This tagging system is desirable because of the low rate of tag loss, lack of mortality or adverse behavior caused by implantation, and the ability of the tags to provide biological information over a long period (Drew et al., 2012). However, implanted PIT tags are small (ca. $10 \mathrm{~mm}$ in length) and are typically made of glass, which might be dangerous for human consumers of tagged crabs. Therefore, this method is undesirable for use in harvested populations. On the other hand, the photo matching method described in the present study is non-invasive, poses no threat to consumers, and is useful for the study of harvested populations. In addition, this method has no unnecessary equipment costs, and is easy to perform. However, this photo-identification method may only be suitable for small numbers of individuals, because this process becomes inefficient with large data sets. Recently, computer software for use in identifying the natural markings of large vertebrates has been developed, e.g., cheetahs, Acinonyx jubatus (Kelly, 2001), and whale sharks, Rhincodon typus
(Arzoumanian et al., 2005). If a similar computer-aided system were to be developed and introduced for coconut crabs, we believe that the gathering of adequate biological data for resource management would be enhanced.

\section{Acknowledgments}

We thank the staff of Okinawa Churaumi Aquarium for assisting us with night searching and rearing management. Y. Iguchi, K. Sato, and K. Miyamoto, of the Okinawa Churashima Foundation, also supported our study. We wish to acknowledge C. Nishihara and E. Maehara for correction of the English manuscript. The field research was carried out with the permission of the Okinawa Commemorative National Government Park Office.

\section{Literature Cited}

Arzoumanian, Z., Holmberg, J., \& Norman, B., 2005. An astronomical pattern-matching algorithm for computer-aided identification of whale sharks Rhincodon typus. Journal of Applied Ecology, 42: 999-1011.

Drew, M. M., Harzsch, S., Stensmyr, M., Erland, S., \& Hansson, B. S., 2010. A review of the biology and ecology of the robber crab, Birgus latro (Linnaeus, 1767) (Anomura: Coenobitidae). Zoologischer Anzeiger, 249: 45-67.

Drew, M. M., Hartnoll, R. G. \& Hansson, B. S. 2012. An improved mark-recapture method using passive integrated transponder (PIT) tags in Birgus latro (Linnaeus, 1767) (Decapoda, Anomura). Crustaceana, 85: 89-102.

Friday, N., Smith, T. D., Stevick, P. T. \& Allen, J., 2000. Measurement of photographic quality and animal distinctiveness for the photographic identification of humpback whales. Marine Mammal Science, 16: 355-374.

Fletcher, W. J., Fielder, D. R., \& Brown, I. W., 1989. Comparison of freeze- and heat-branding techniques to mark the coconut crab Birgus latro (Crustacea, Anomura). Journal of Experimental Marine Biology and Ecology, 127: 245-251.

1990. Growth of the coconut crab Birgus latro in Vanuatu. Journal of Experimental Marine Biology and Ecology, 141: 63-78.

Gallardo-Escarate, C., Coldstein-Vasquez, J., \& Thiel, M., 2007. Individual identification of 
decapod crustaceans I: Color patterns in rock shrimp (Rhynchocinetes typus). Journal of Crustacean Biology, 27: 393-398.

Gope, C., Kehtarnavaz, N., Hillman, G., \& Wursig, B., 2005. An affine invariant curve matching method for photo-identification of marine mammals. Pattern Recognition, 38: 125-132.

Gosselin, T., Sainte-Marie, B., \& Sevigny J. M., 2007. Individual identification of decapod crustaceans II: Natural and genetic markers in snow crab (Chionoecetes opilio). Journal of Crustacean Biology, 27: 399-403.

Kelly, M., 2001. Computer-aided photograph matching in studies using individual identification: an example from Serengeti cheetahs. Journal of Mammalogy, 82: 440-449.

Krieger, J., Grandy, R., Drew, M. M., Erland, S., Stensmyr, M. C., Harzsch, S., \& Hansson, B. S., 2012. Giant robber crabs monitored from space: GPS-based telemetric studies on Christmas Island (Indian Ocean). Plos One, 7: 1-14.

MacDiarmid, A. B., Oliver, D., Stewart, R. A.,
\& Gopal, D., 2005. Conservation of unique patterns of body markings at ecdysis enables identification of individual spiny lobster, Jasus edwardsii. New Zealand Journal of Marine and Freshwater Research, 39 (Special Issue no 2): 551-555.

Sato, T., Yoseda, K., Abe, O., Shibuno, T., \& Hamasaki, K. 2013. Growth of the coconut crab Birgus latro estimated from mark-recapture using passive integrated transponder (PIT) tags. Aquatic Biology, 19: 143-152.

Addresses: (SO) (SM) (MT) Okinawa Churashima Foundation, 888 Ishikawa, Motobu-cho, Okinawa 905-0206, Japan.

E-mails: (SO)sh-oka@okichura.jp

ReCeIVED: 4 June 2013.

ACCEPTED: 7 November 2013. 